\title{
Investigating projectile penetration of sandwich panels with multiple suppressive cores
}

\author{
M. Y. Laissy ${ }^{1}$, W. A. Attia ${ }^{2} \&$ M. M. Abdel-Wahab ${ }^{3}$ \\ ${ }^{I}$ Faculty of Engineering, MTI University, Egypt \\ ${ }^{2}$ Structural Engineering Department, Faculty of Engineering, \\ Cairo University, Egypt \\ ${ }^{3}$ Head of the Technical Research Institute, Egyptian Armed Forces, Egypt
}

\begin{abstract}
Concrete structures are employed extensively in protective structures. This concept does not guarantee economic benefits to reduce the construction time or cost. An important issue is how the penetration distance will be affected when using sandwich panels with multiple suppressive cores. This paper presents the development of an accurate finite element model using AUTODYN to study the behaviour of different sandwich panels exposed to $23 \mathrm{~mm}$ projectile. Concrete and steel are modelled as Lagrangian meshes while air is modelled as Eulerian mesh. Experimental tests and numerical analysis were carried out to examine the penetration depth of the different suppressive cores used. The result of this paper will prove the benefits of using the sandwich panels with multiple suppressive cores in reducing the penetration depth of the $23 \mathrm{~mm}$ projectile. Experimental tests will validate the presented models. Further experiments to validate the effect of the steel angles arrangement presented herein will be conducted and reported at a later stage.
\end{abstract}

Keywords: sandwich panels, suppressive core, penetration, concrete, projectiles.

\section{Introduction}

Reinforced concrete and steel are still the most common materials used in protective structures, since massive concrete structures withstand blast waves and fragment impacts effectively; they are often used as protective structures 
according to Swedish Shelter Regulations [1]. The traditional design of the structures under the impact loads effects is a cumbersome process and takes great efforts to finalize the computations. So, the output of the final traditional design gives too heavy weight of the steel and concrete elements, which causes many problems in the budget, time and effort done to establish a site.

A concrete structure subjected to impact loading will have different response than those statically loaded. When fragments fly into a concrete target, spalling occurs in the front of the concrete surface as a result of the direct impact. The purpose of this paper is to study the response of sandwich panels with multiple suppressive cores exposed to heavy dynamic loads to be of reasonable weight and high resistance against impact loads.

In order to get better understanding for the behavior of impact loads on the suppressive materials during penetration process, it was very essential to produce finite element models for the experimental specimens. The software package AUTODYN-3D is used in simulating the penetration of projectiles into these specimens.

The primary objective of this paper is to study the ability of sandwich panels with multiple suppressive cores to resist the penetration of $23 \mathrm{~mm}$ projectile. Report on numerical and experimental data of penetration problems on sandwich panels and the penetration depth will be illustrated.

\section{Penetration and perforation projectiles}

The penetration of projectiles into targets involves complex mechanical interactions. By convention [2] the following simplifying definition are adopted. When a projectile enters a target did not passes through it so this projectile it is said 'penetrated'. On the other hand, when a projectile passes completely through a target, it is said 'perforated'. The depth of penetration is given by the distance as shown in fig. 1 .
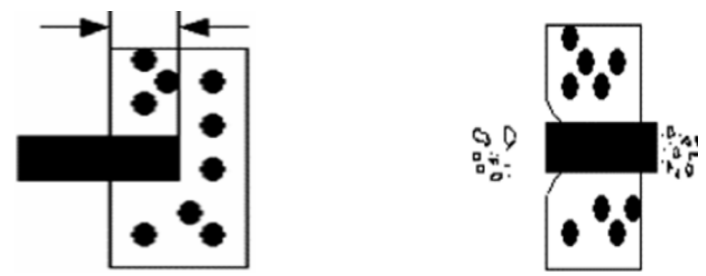

Figure 1: $\quad$ Penetration and perforation phenomena.

\section{Experimental test set up}

The gas gun test was carried out to investigate the penetration depth of the concrete model exposed to ballistic impact as shown in fig. 2. This test was carried out according to laboratories of USA army corps of engineering (ACE) using an Aircraft $23 \mathrm{~mm}$ cannon as shown in fig. 2. The used projectile was 
blunt-nose steel penetrator $23 \mathrm{~mm}$ diameters and $64 \mathrm{~mm}$ length as shown in fig. 4 which illustrates the dimension and details of the penetrator, the material prosperities of the penetrator are listed in table 1 . The impact velocity was measured and reported for every shot with electro-optical velocity measurement device which is connected with computer as shown in fig. 5 and fig. 6 it was $969 \mathrm{~m} / \mathrm{sec}$.

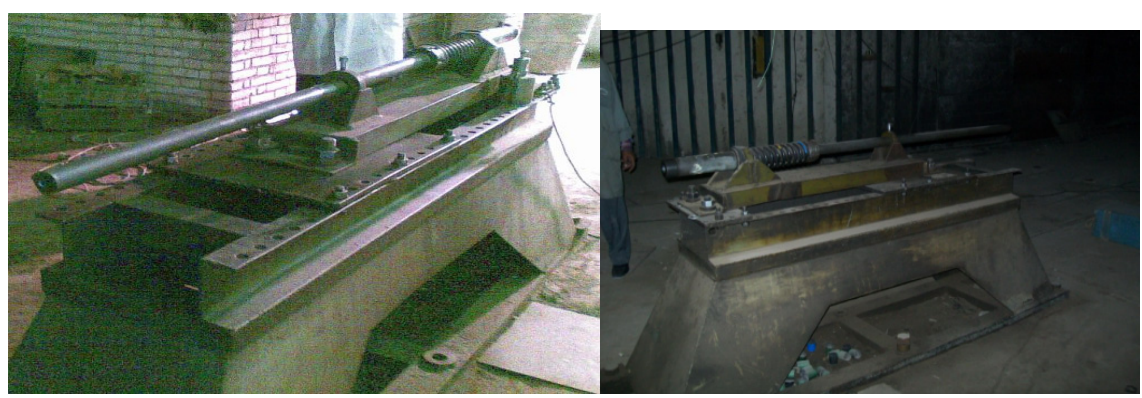

Figure 2: $\quad$ Aircraft $23 \mathrm{~mm}$ cannon.

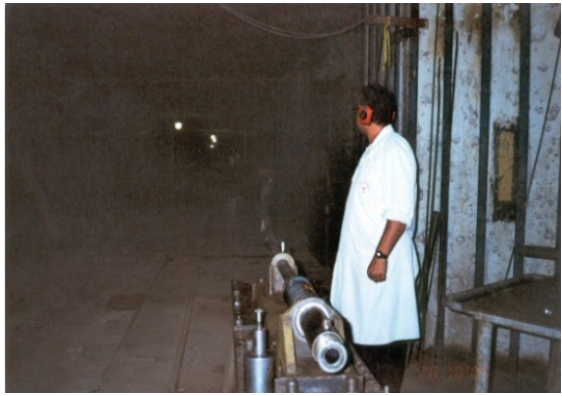

Figure 3: $\quad$ Aircraft $23 \mathrm{~mm}$ cannon. Figure 4:

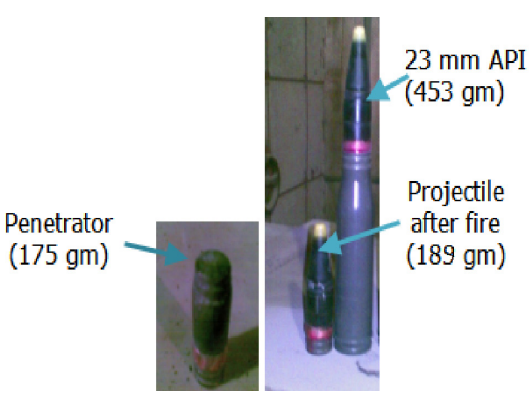

Different firing stages of $23 \mathrm{~mm}$ API projectile.

Table 1: $\quad$ Mechanical properties of the 23 AP projectile materials.

\begin{tabular}{|c|c|c|c|}
\hline $\begin{array}{c}\text { Brinell hardness } \\
\text { Number }[\mathrm{HB}]\end{array}$ & $\begin{array}{c}\text { Yield strength } \\
{[\mathrm{MPa}]}\end{array}$ & $\begin{array}{c}\text { Ultimate strength, } \\
{[\mathrm{MPa}]}\end{array}$ & $\begin{array}{c}\text { Strain to fracture } \\
{[\%]}\end{array}$ \\
\hline 475 & 1726 & 1900 & 7 \\
\hline
\end{tabular}




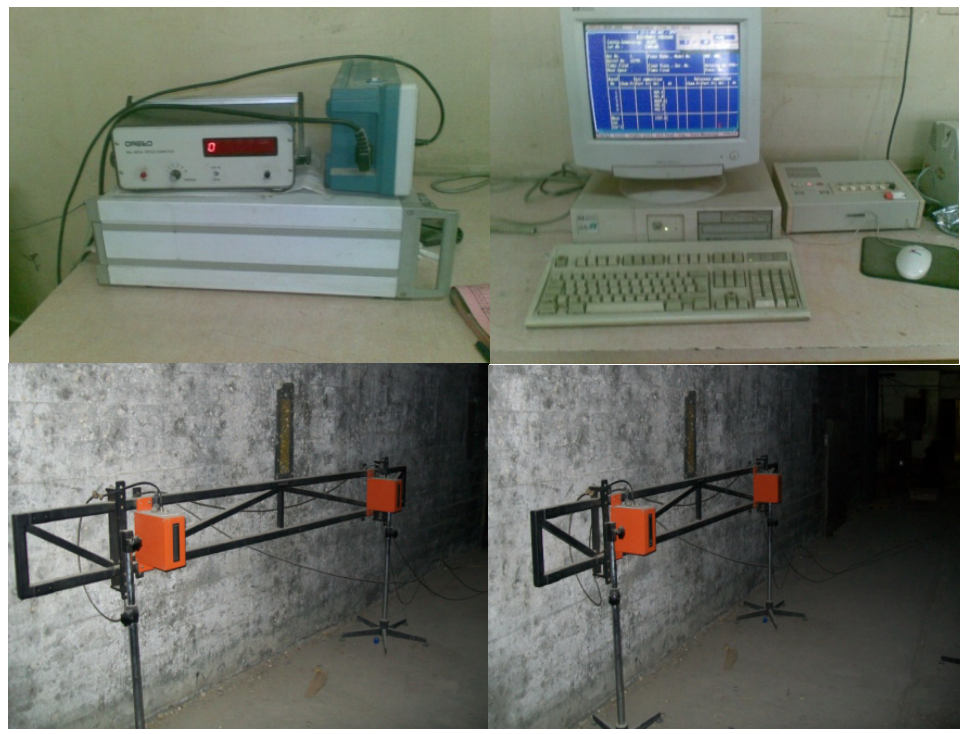

Figure 5: Velocity measurement device.

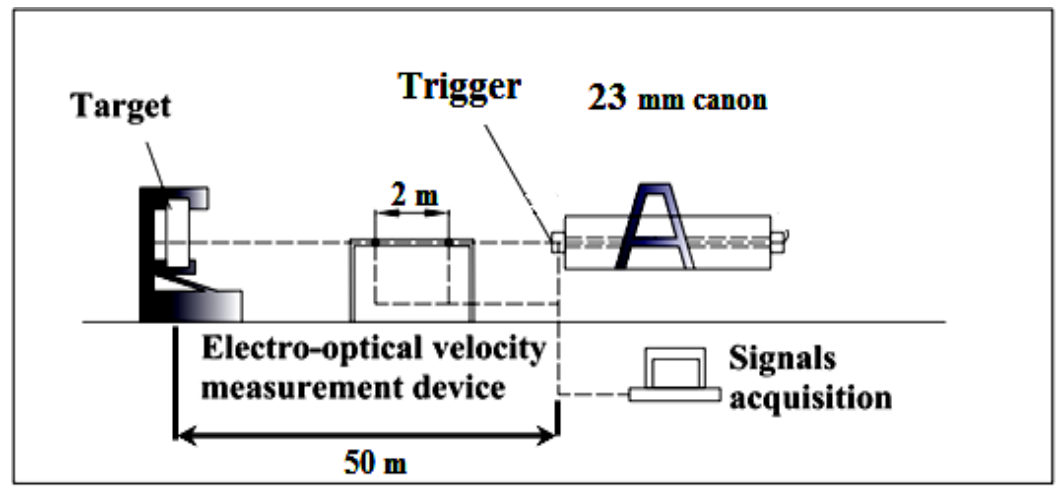

Figure 6: Penetration depth setup for concrete.

The illustrated test models in figures 7 and 9 were formed of a concrete block with the dimension of $(0.3 \mathrm{~m} \times 1.0 \mathrm{~m} \times 1.0 \mathrm{~m})$ and a steel angles block of four rows with the block dimensions of $(0.3 \mathrm{~m} \times 1.0 \mathrm{~m} \times 1.0 \mathrm{~m})$. The concrete boundary condition was fixed from the backside, the steel angels block boundary condition was fixed from two sides and the $23 \mathrm{~mm}$ projectile has a Z-velocity initial condition of $969 \mathrm{~m} / \mathrm{s}$. Two experiments were done depending on the penetration point of the $23 \mathrm{~mm}$ projectile Model "A" and Model "B". 


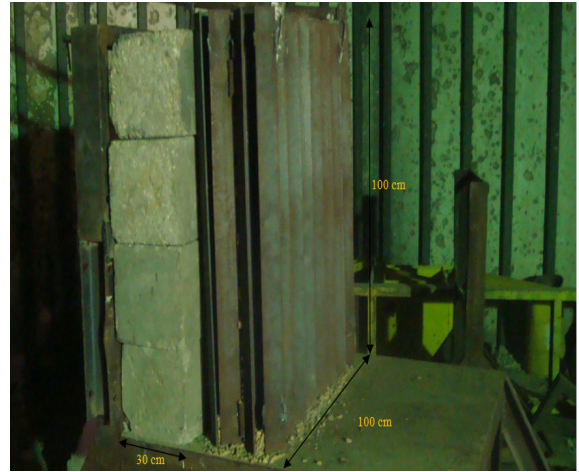

Figure 7: Details of penetration model "A".

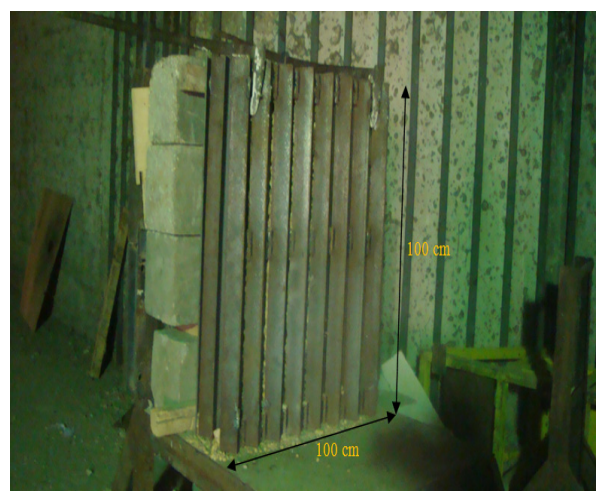

Figure 9: Details of penetration model "B".

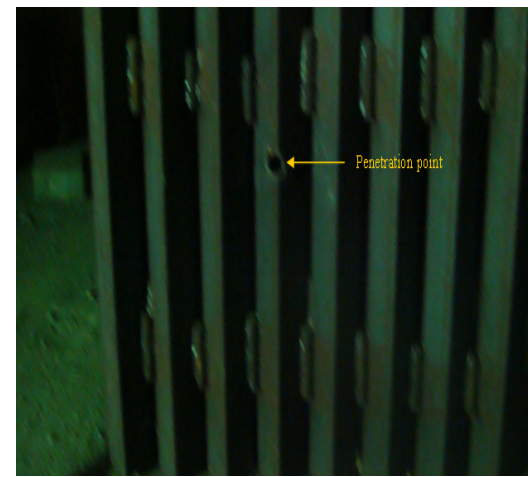

Figure 8: Penetration point for model "A".

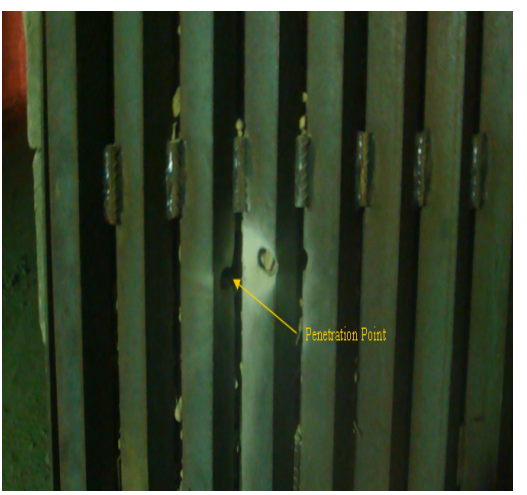

Figure 10: Penetration point for model "B".

\subsection{Experimental test result}

For model "A", the $23 \mathrm{~mm}$ projectile has perforated from two rows of angles and penetrated into the third row before stopping on the fourth row as the Z-velocity as well as the Z-force decline to reach zero.

For model "B", the $23 \mathrm{~mm}$ projectile has perforated from four rows of angles and scratched the concrete block before stopping and the Z-velocity as well as the Z-force decline to reach zero as shown in fig. 11. 


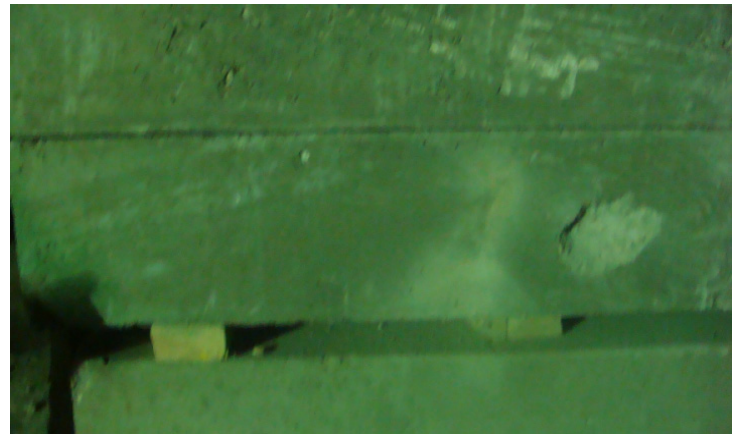

Figure 11: Details of concrete scratch for model "B".

\section{Numerical analysis}

\subsection{Description of finite element model}

The program AUTODYN [3] was used to create finite element model for the previous experimental model. This was to simulate the penetration process of projectiles into the model. The material or component is discredited into forming cells or meshes. Each mesh interacts with another one by defined strength model for each material that has an equation of state. The line of interaction between materials is defined; time step is determined in order to satisfy the stability condition for the problem. Finally, a matrix of unknowns is solved for non-linear system indicating each effect of stresses on the whole materials.

\subsection{Material description}

The material model used to simulate the projectile in the model is (STEEL 4340), for plain concrete material (Conc.35MPa) was used and for steel angles material (STEEL 1006) was used these materials were chosen from the AUTODYN library. For Steel, the equation of state used is linear equation of state, and the strength model is Johnson Cook strength model, whereas the failure model was (None) and the erosion model was selected to be Instantaneous geometrical strain. The data defines of the penetrator material in the hydrocode were chosen from the library and modified, according to used material listed in table 2.

Table 2: $\quad$ The data defines the projectile materials.

\begin{tabular}{|l|c|l|c|}
\hline Reference Density (gm/cm3) & 7.83 & Hardening constant $(\mathrm{Kpa})$ & $1.7851 \mathrm{E} 7$ \\
\hline Bulk Modulus (Kpa) & $1.67 \mathrm{E} 8$ & Hardening exponent & 0.26 \\
\hline Reference temperature (K) & 300 & Strain rate constant & 0.014 \\
\hline Specific heat (C.V.) (j/kgK) & 477 & Thermal softening exponent & 1.03 \\
\hline Shear modulus (Kpa) & $7.98 \mathrm{E} 7$ & Melting temperature $(\mathrm{k})$ & 1793 \\
\hline Yield stress (Kpa) & $1.726 \mathrm{E} 6$ & Ref. Strain Rate (/s) & 1 \\
\hline
\end{tabular}


For Concrete, the equation of state used is P-Alpha equation of state, and the strength model was RHT CONCRETE strength model, whereas the failure model was RHT CONCRETE "Strength Model for the Concrete" and the erosion model was selected to be Instantaneous geometrical strain. The data defines of the concrete material in the hydrocode were chosen from the library and modified, according to the used material listed in table 3.

Table 3: Data defines the concrete materials.

\begin{tabular}{|c|c|c|c|}
\hline $\begin{array}{l}\text { Porous density } \\
\left(\mathrm{gm} / \mathrm{cm}^{3}\right)\end{array}$ & 2.75 & Failure Surface parameter A & 2 \\
\hline $\begin{array}{l}\text { Porous } \\
\text { density }\left(\mathrm{gm} / \mathrm{cm}^{3}\right)\end{array}$ & 2.314 & Failure Surface exponent N & 0.7 \\
\hline $\begin{array}{l}\text { Porous sound speed } \\
(\mathrm{m} / \mathrm{s})\end{array}$ & $2.92 \mathrm{E} 3$ & Tens./Comp. Meridian Ration & 0.6805 \\
\hline $\begin{array}{l}\text { Initial compaction } \\
\text { pressure (Kpa) }\end{array}$ & $2.33 \mathrm{E} 4$ & Brittle to Ductile Transit & 0.0105 \\
\hline $\begin{array}{l}\text { Solid compaction } \\
\text { pressure (Kpa) }\end{array}$ & $6 \mathrm{E} 6$ & G (elas.)/G (elas.-plas.) & 2 \\
\hline Compaction exponent $\mathrm{n}$ & 3 & Compaction curve & Standard \\
\hline Solid EOS & Polynomial & Elastic Strength $/ \mathrm{ft}$ & 0.7 \\
\hline $\begin{array}{l}\text { Bulk Modulus A1 } \\
(\mathrm{kPa})\end{array}$ & $3.527 \mathrm{E} 7$ & Elastic Strength /fc & 0.53 \\
\hline Parameter A2 $(\mathrm{kPa})$ & $3.958 \mathrm{E} 7$ & Use cap on Elastic Surface & 1 \\
\hline Parameter A3 (kPa) & $9.04 \mathrm{E} 6$ & Residual Strength Const. B & 1.5 \\
\hline Parameter B0 & 1.22 & $\begin{array}{l}\text { Residual Strength exponent } \\
\text { M }\end{array}$ & 0.61 \\
\hline Parameter B1 & 1.22 & $\begin{array}{l}\text { Comp. Strain Rate Exponent } \\
\text { a }\end{array}$ & 0.032 \\
\hline Parameter T1 $(\mathrm{kPa})$ & $3.527 \mathrm{E} 7$ & Tens. Strain Rate Exponent D & 0.025 \\
\hline Parameter T2 (kPa) & 0 & Max. Fracture strength Ratio & $1 \mathrm{E} 20$ \\
\hline $\begin{array}{l}\text { Reference temperature } \\
(\mathrm{K})\end{array}$ & $3 \mathrm{E} 2$ & Damage Constant D1 & 0.04 \\
\hline $\begin{array}{l}\text { Specific heat (C.V.) } \\
(\mathrm{j} / \mathrm{kgK})\end{array}$ & $6.54 \mathrm{E} 2$ & Damage Exponent D2 & 1 \\
\hline Shear modulus $(\mathrm{kPa})$ & $1.67 \mathrm{E} 7$ & Min. strain to failure & 0.01 \\
\hline $\begin{array}{l}\text { Compressive strength } \\
\mathrm{fc}(\mathrm{kPa})\end{array}$ & $3.50 \mathrm{E} 4$ & $\begin{array}{l}\text { Residual Shear Modulus } \\
\text { Frac. }\end{array}$ & 0.13 \\
\hline Tensile strength $\mathrm{ft} / \mathrm{fc}$ & 0.088 & Tensile Failure Model & $\begin{array}{l}\text { Hydro } \\
\text { Tens. }\end{array}$ \\
\hline Shear strength fs/fc & 0.18 & Erosion strain & 0.7 \\
\hline
\end{tabular}




\subsection{Geometry and mesh description}

Lagrange processor has been used in AUTODYN for the analyses. In this paper the considered target panels was sandwich panel with multiple suppressive core. Projectile and the sandwich panel target are modeled as Lagrangian meshes in the model. All parts were symmetric on $\mathrm{X}=0$ and $\mathrm{Y}=0$ planes to reduce the size of the computational domain. The geometry of the projectile part is defined in the model using a structural Lagrangian mesh. Due to the symmetric conditions, The projectile geometry, which is $23 \mathrm{~mm}$ diameter and $64 \mathrm{~mm}$ length is modeled as a $1 / 4$ cylinder, it was divided to nodes in the $\mathrm{I}, \mathrm{j}, \mathrm{k}$-directions. This IJK-index is known as a Cartesian co-ordinate system fig. 12, shows the geometry and mesh description for the projectile part.

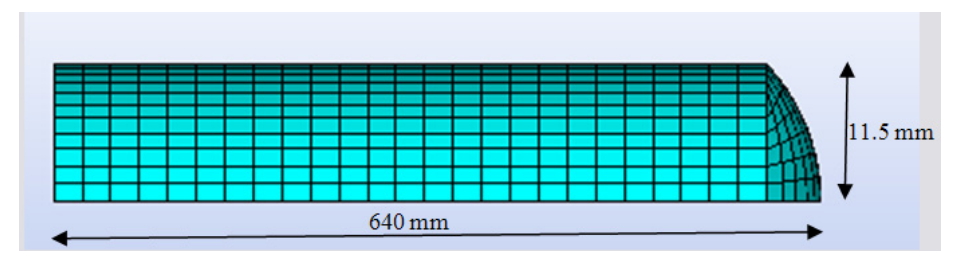

Figure 12: $23 \mathrm{~mm}$ API projectile mesh.

The penetration model was formed of steel angles block of four rows and concrete block as illustrated in figs.13 and 15. The model boundary condition was fixed from the back side and the $23 \mathrm{~mm}$ projectile has a Z-velocity initial condition of $969 \mathrm{~m} / \mathrm{s}$. The model and the projectile were meshed into nodes and elements to produce accurate results, figs.14 and 16.

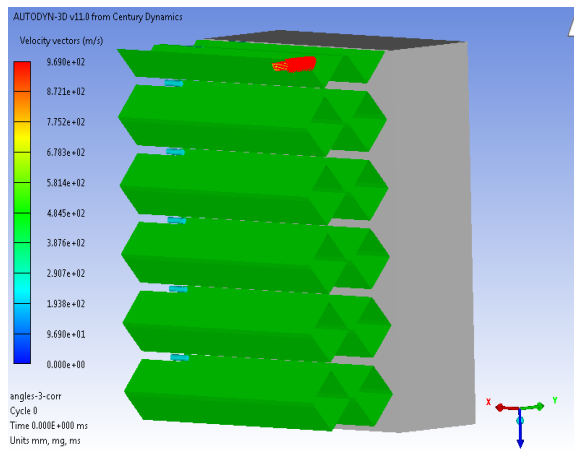

Figure 13: Details of model "A".

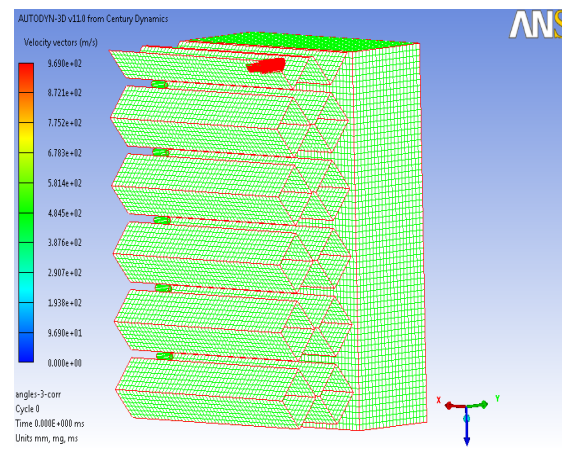

Figure 14: Details of meshed model "A". 


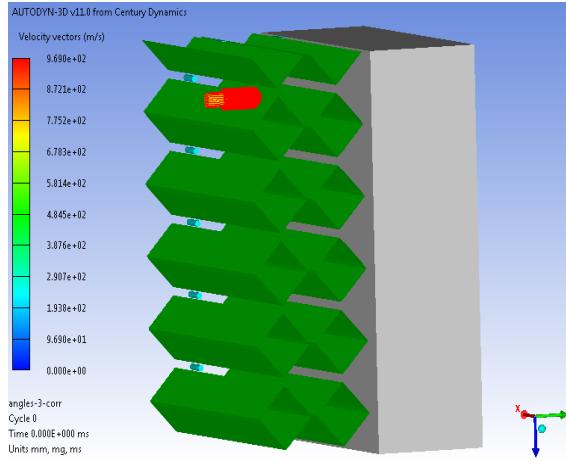

Figure 15: Details of model "B".

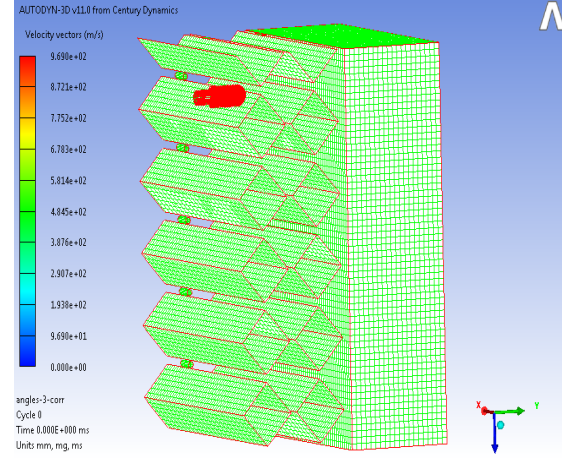

Figure 16: Details of meshed model "B".

\subsection{Numerical test results}

For model "A", the $23 \mathrm{~mm}$ projectile has perforated from two rows of angles and penetrated into the third row before stopping as the Z-velocity as well as the Zforce decline to reach zero as shown in fig. 17.

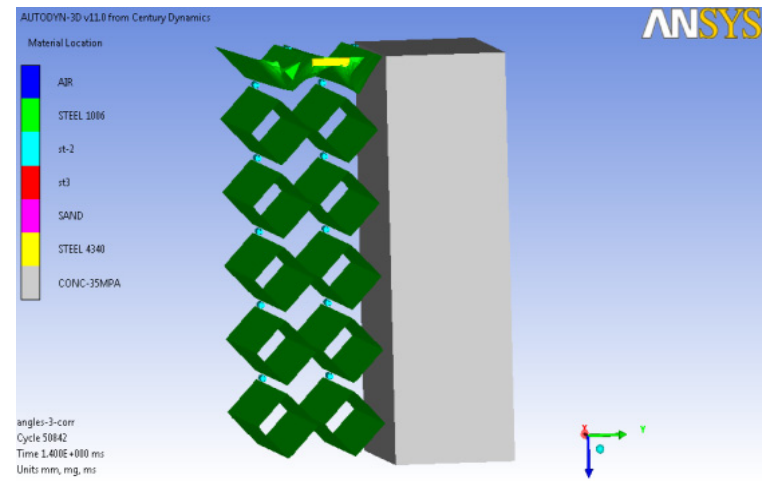

Figure 17: Details of projectile penetration of model "A".

For model "B", the $23 \mathrm{~mm}$ projectile has perforated from four rows of angles and scratched the concrete block before stopping and the Z-velocity as well as the Z-force decline to reach zero as shown in figs. 18 and 19. 


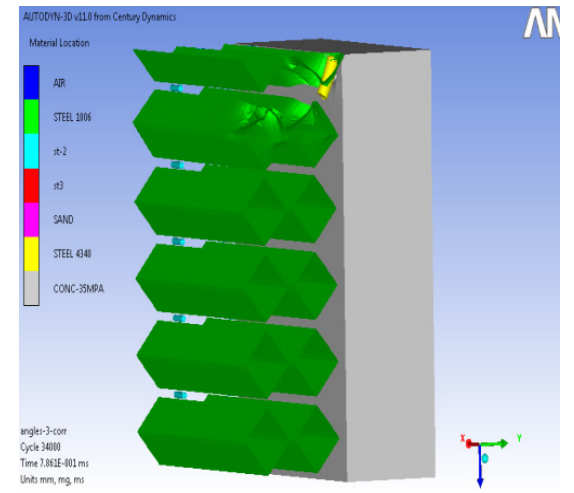

Figure 18: Details of projectile penetration of model "B".

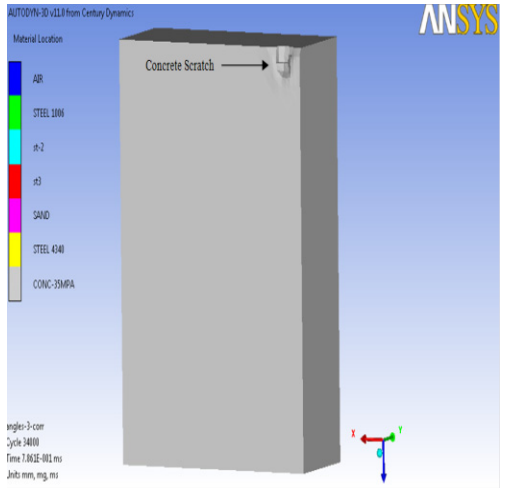

Figure 19: Details of concrete scratch for model "B".

\section{Conclusion}

From the previous study, the following conclusion can be drawn out:

1. The AUTODYNE code satisfactory simulates the penetration experimental tests.

2. The response of concrete panel under the penetration load can be simulated using ANSYS software, it has the advantage, and thus it has higher analysis precision, compared to the common analysis.

3. Steel angles rows arranging did reduce the projectile penetration distance by $20 \%$.

4. The sandwich panels with suppressive cores are highly recommended for protective structures due to its high energy dissipation by steel angles and absorption by concrete.

\section{References}

[1] Ekengren, B.: "Shelter Regulations", English edition, Swedish Rescue Services Board, Publication B54-168/94, Karlstad, Sweden; 1994, pp. 94.

[2] Hetherington, J.G. and Smith. P. D.: "Blast and Ballistic Loading of Structures", 1 st Ed., Butterworth-Heinemann, ISBN 0-7506-2024-2, Oxford, UK, 1994.

[3] "AUTODYN Interactive Non-Linear Dynamic Analysis software", Theory Manual, Century Dynamics Company, Inc., 2005. 